\title{
Space Technologies of Life Support Systems for the Metropolitan Cities
}

\author{
N. Buzalo ${ }^{a}$, A. Bulgakov ${ }^{b}$ and T. Bock ${ }^{c}$ \\ ${ }^{a}$ South Russian State Technical University, Novocherkassk, Russia \\ ${ }^{b}$ South West State University, Kursk, Russia \\ ${ }^{c}$ Technical University of Munich, Germany \\ E-mail: n.s.buzalo@mail.ru, a.bulgakow@gmx.de, Thomas.Bock@bri.arch.tu-muenchen.de
}

\begin{abstract}
-
The paper deals with the use of biological life support systems, initially created for long-duration space flights $[1,2]$, for the solution of problems with the sustainability of metropolitan cities, which must meet the requirements of decrease of environmental load. Motivated by applications in issues of design of water purification stations for new generation of high-rise buildings "Sky City" this research considers the questions of the simulation and control of artificial ecosystems. As mathematical formalism to describe and control the processes in a bio purification station, we use the general form of conservation laws of matter in the form of the Reaction-Convection-Diffusion Equation System [3, 4, 5] and optimisation problems for it. The main types of schemes of life support systems for space stations have been discussed. Much attention has been paid to the question of creating bioreactors, which can be used for water purification within residential building. The simulation and control of artificial ecosystems has been discussed.
\end{abstract}

Keywords -

Space Technologies, Life Support Systems, Metropolitan Cities, Mathematical Modelling of Ecosystems

\section{Introduction}

Growing constantly, modern megacities and urban agglomerations exert extremely high environmental load. Numerous skyscrapers that form city skylines and high density of buildings lead to disruption of the ecological balance of the city and the territory in which it is located, as well as and the self-repairing functions of city ecosystems. Also, one of the biggest problems of megalopolises is the human-waste disposal. In modern conditions, traditional sewer and wastewater treatment systems are very expensive, occupy vast territories, and do not always operate reliably. Occasionally, wastewater discharges to water bodies lead to exceeding the maximum permissible concentrations of pollutants. According to United Nations Environment Programme, the state of the environment is the direct cause of about $25 \%$ of ailments all around the world, and the most common among them are gastrointestinal and acute respiratory infections. Cause of $7 \%$ of deaths and disease is poor water quality and poor sanitation $[6,7]$.

Nowadays new generation building projects intended to 100-200 thousand inhabitants are being developed actively. Let us call them Sky-City-buildings. Under current technology, such amount of people makes sewer system load of the order of $0.6-1 \mathrm{~m}^{3} / \mathrm{c}$ and requires about 8-10 hectares of treatment plant area. We propose a new concept of small-volume local treatment facilities, which provide almost complete recycling of substances, and can be used for water purification within Sky-City-buildings. The main features of the concept are the small volume of purification system, its local position on a floor in close proximity to inhabitants, recycle of substances and energy (closedloop treatment facilities).

Small volume of treatment facilities is a significant advantage from point of view preservation of the wildlife areas, the possibility of refusal to use a sewer network, increasing the motivation to economy and responsibility of each water user. Further such kind of facilities can be integrated into self-sustaining, interchangeable and standardized platform, which is situated beneath a modular home, a so-called mainboard- inspired one, by the principle of computing, which houses and electronically controls all water installments and energy components needed for a household [8].

Idea of the article is the use of technology developed for space under ground conditions. No other field of science has influenced imagination and vision more than the research and outcomes related to space exploration, either it is in terms of science fact, or science fiction. Analysis of the opportunities and prospects of using various space technologies for designing the systems on the Earth that may be 
described as being sustainable has been given in [9]. Background of our project is experience in creating closed ecological systems as parts of biological life support systems (LSSs) for space ship.

We have applied the idea of creating some isolated volume suitable for long-term survival of man to the Earth conditions, for example, a volume located in a skyscraper.

\section{Life Support Systems for Space Stations}

To date, life support systems that allow human to exist inside the hermetically closed volume for a long time have been created and exploited. Such systems fully provide human with water, oxygen and remove wastes. There are four kind of LSSs for a spacecraft (Figure 1): the system with reserves where all waste is removed, the system with reserves and partial physicalchemical regeneration of substances, the system with partial substance regeneration by living organisms (bioregeneration), and the closed-loop system.

Currently models with partial physical-chemical regeneration of substances is being used at the International Space Station. These LSSs can function only in the presence of constant communication with the biosphere of the Earth, as they are based on the stocks of materials, so the duration of human existence in them depends on the amount of reserves or the possibility of their constant replenishment. Since the beginning of the space age, it was evident that for long interplanetary spaceflight and planetary bases (settlements), when the connection with the biosphere of the Earth is completely absent, LSS must be built on a fundamentally different basis.

The basis of LSS for a long-duration flight should be the principle of regeneration of the human's environment. Long-term work on the creation of human's life-support system has showed that it is easier to implement regenerative system based on biological principle rather than on the basis of physical-chemical processes. Attempts to develop such kind of systems started in USSR in the late 50's. As a result, by the current moment, different models of LSS based on the biological cycle of substances have been created and tested in Earth conditions [10].

In 1975, Eugeniy Shepelev introduced the concept of closed ecological life support system as the hypothetical biological system that exists on the basis of a closed cycle of substances without material exchange across its borders. To date, the feasibility of constructing of closed ecological LSSs that meet all needs of the person has been proved

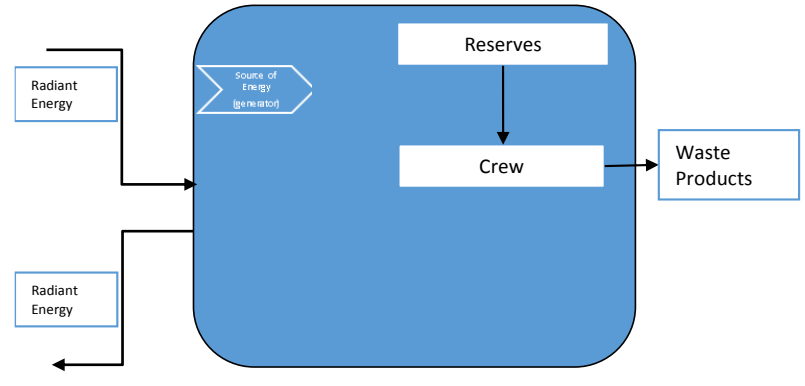

System with Reserves (all waste is removed)

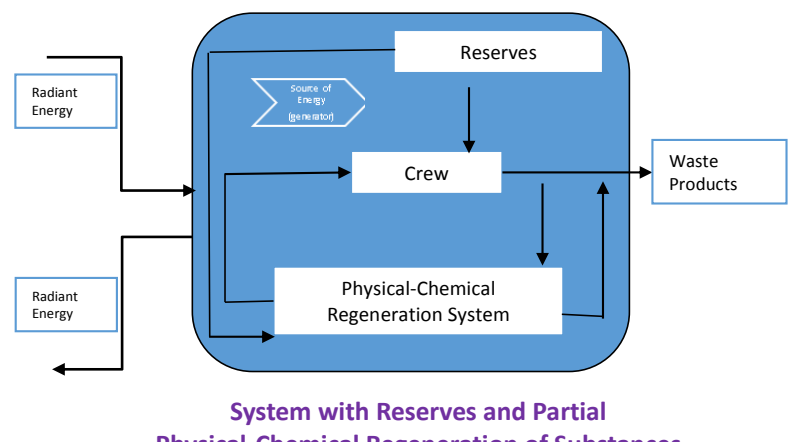

Physical-Chemical Regeneration of Substances

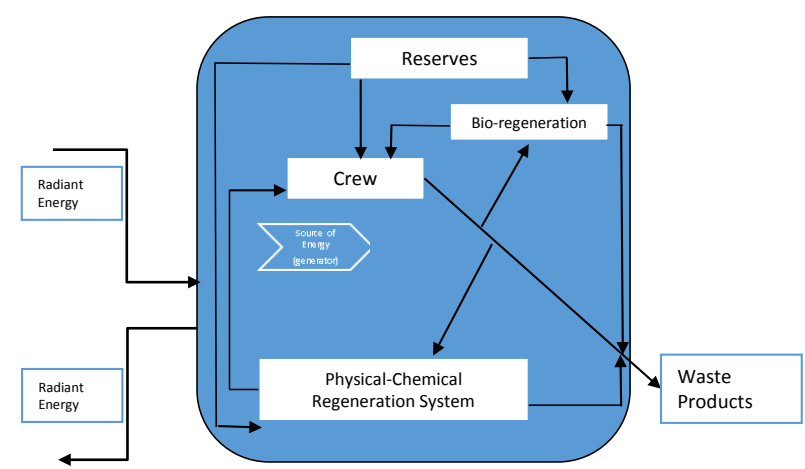

System with Partial Substance Regeneration by Living Organisms (Bio-regeneration)

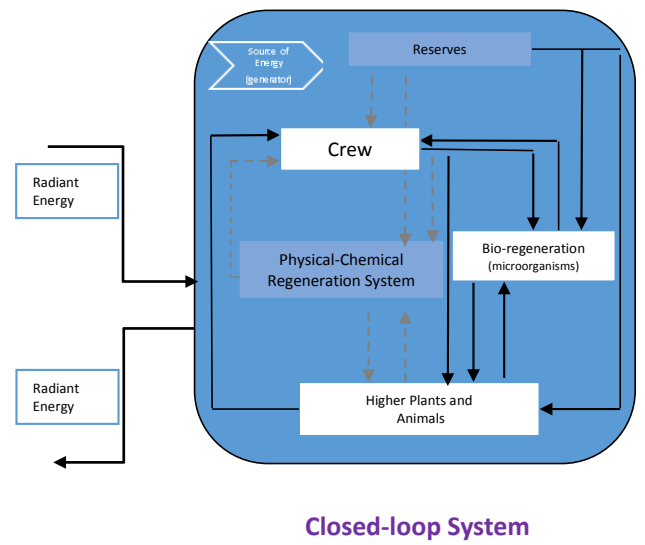

Figure 1. Schemes of the main types of Life Support Systems 
During the 60s - 80s, at Institute of Biomedical Problems and Institute of Biophysics of Russian Academy of Sciences, there were several experiments with systems based on the following links of the ecological chain: algae - mineralization human and algae - mineralization - higher plants human.

As the project being implemented currently, should be mentioned the MELiSSA -project (Micro-ecological life-support system) of the European Space Agency. In this project, scientists plan to include one more heterotrophic link - animals, namely fishes [1]. Whereas attempts to create a similar system on the basis of physical-chemical processes are still not successful. To date, there are only different elements (subsystems, components, assemblies, etc.) but there is no regenerative systems based on physical-chemical processes as a whole.

It should be noted that in spite of the successful experiments, the closed ecological life support system based on a biological cycle of substances are not used in practical astronautics. That is due to the facts that their operation requires high power consumption, as well as large areas, volumes, initial weight (especially for systems with higher plants), and there is no technology of work with living organisms in space flight conditions (in weightlessness). However, these factors are not essential in our case. Key processes of LSS are the recycling of inedible biomass, human waste (feces, and urine), carbon dioxide and minerals and the production of food, fresh water, and air revitalization, while functions of the system developed for use in skyscrapers are much narrower. We have only the following objective: recycling of human waste for fresh water production. There is no weightlessness, the need to produce food, oxygen deficiency. Thus, we have to solve the problem of high energy consumption only. However, on the Earth, it is possible to close the system through the process of oxidation (combustion) of biomass for generation energy. Another problem that is still constraining the design of similar systems is the fact that in contrast to the conditions at the space station, for an ordinary city building, it is pretty difficult to predict effluent precisely enough for creation a stable and efficient system.

\section{The Project Concept}

Making a start from the effective experience of closed ecological LLS creation in USSR, we design the idea of local small volume biological treatment facilities with maximum-closed cycle of substances. The purpose of our work is to develop of biological treatment facilities based on a closed-loop cycle for ultra-small waste effluent of about 30 people for using in civil engineering.

Since the main difference of the system is a high degree of closure of flows then the hardest part is to balance all the technological processes. The basic idea that allows us to overcome this difficulty is creation of an automatic control system of the treatment facilities on a base of sufficiently accurate mathematical model describing concentration substances in an artificial aquatic ecosystem of the purification system. Thus, the adequate simplicity and the possibility of describing the purification process via laws of matter conservation is one of the main requirements for the system being developed.

In all types of closed ecological LLSs, algae is a basic element (link) of LLS, which allows regenerating the air, and water completely and provides $[2,10]$ :

- Partial nitrogen cycle by way of the full use of human urine nitrogen by unicellular algae.

- Optimization of air ion and aerosol composition of the atmosphere.

- $\quad$ Stabilizing of content of water-insoluble impurities (methane, carbon monoxide, etc.) by way their adsorption on the algae cell and microorganism surface and the subsequent removal of the grown biomass from the system.

- Ousting microflora, including pathogenic to humans, from micro biocenosis by a competitive relationship.

- If applicable, the names of other authors, having different affiliations and addresses, in the same format used for the first author.

- Cleaning the atmosphere of a hermetic volume from various water-soluble gaseous contaminants through their full absorption and utilization in a photo-reactor by algae and attendant microorganisms (photo-reactor is an universal resettable hydrobiological filter).

Multifunctionality of biological regeneration processes of the human environment is an additional argument to use algae as a main element of water purification systems located within the building.

For our purification system, the structure Microalgae-Human-Mineralization as the simplest option has been chosen. In this case, it is possible to consider our treatment plant as a set of artificial aquatic ecosystems. Components of aquatic ecosystems is not different functionally from the components of terrestrial ecosystems. However there are some features. Organisms in the water biochemically are closely related to their environment and depend on the concentration of soluble substances. Due to the water 
density, which is the considerably greater than of air, many aquatic organisms are free-floating. The water consists of spatial-distributed suspended substances, microalgae, and microbes. The water also creates the possibility of biochemical links between communities of hydrobionts through the allocation of many organisms oxygen, carbon dioxide and various metabolic products into the water. These substances, toxic, or, on the contrary, stimulating other organisms, form the network by which organisms are connected implicity, without direct contact. This feature of aquatic ecosystems allows describing their processes quite efficiently via the laws of matter conservation in the form of ReactionAdvection-Diffusion equations. As a result, we have an effective tool to create a reliable system for monitoring and control.

The functional diagram of the model MicroalgaeHuman-Mineralization is shown in Figure 2. The diagram has a simplified form but reflects the main streams of matter.

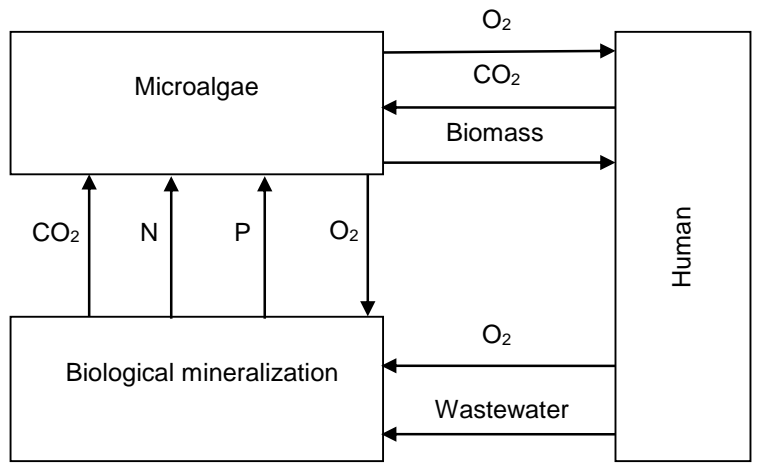

Figure 1. Functional diagram of the model

Stability and reliability of the structure MicroalgaeHuman-Mineralization is implemented by controlled flow circulating between a bioreactor-mineralizer and photoreactor cultivating algae. This combination of systems copies the natural self-purification processes, but which are intensified many times over.

The structure can be integrated into a residential building in the form of the following combinations of elements presented in Figure 3.

In Figure 3, there are the Arabic numerals depict the technological elements and the Roman numerals are the major flows substances. Namely: 1 is a photobioreactor cultivating algae, 2 is a solar concentrator, 3 is a circular bioaeration tank (a mineralizer), 4 is a desilter, 5 is an air-saturator, 6 is an air-blower, 7 is a circulation pump, 8 is an air valve, 9 is a distribution system, I is the waste water, II is air, III is flue gases, IV is the purified water, $\mathrm{V}$ is regenerated air with a high oxygen content, VI is the surplus sludge, VII is algae biomass.

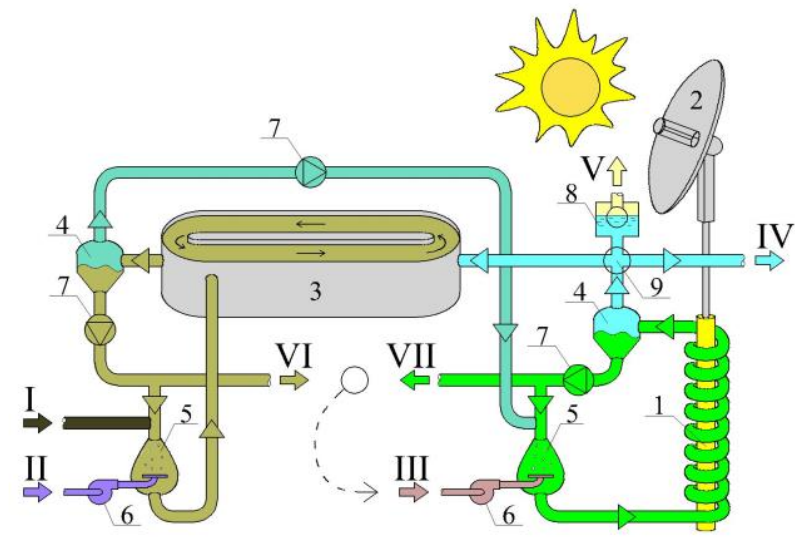

Figure 3. Technological scheme of purification system

The key unit, the point of control in the system is the distribution system 9. Organic substances are oxidized in the mineralizer 3 , mainly due to oxygen, which is formed in the photobioreactor. Separation of sludge biomass occurs in a desilter one part goes back into the reactor, and the excess is removed from the system. By regulating the flow rate of the oxygenated water returning into the system, we can control efficiency of the purification process. In the dark, the additional air supply can be carried out through the saturator 5 . Saturator is a necessary device for dissolution of oxygen. As well as the flow rate of the oxygenated water coming into the unit 3 from the unit 4 , the flow rate of air blown into the element 5 is a control parameter.

The idea of using photoreactors for tertiary sewage treatment within the traditional treatment plants appeared several years ago. There are a number of research and pilot projects, however, still no successfully implemented, cost-effective industrial objects [11]. In developing the technological schemes of functioning of photoreactors being part of the treatment facilities usually there is the need to reduce the growth rate of algae biomass. We propose to use a different concept. All biomass formed as a result of the purification process can be processed into biofuel and provide a source of clean energy. According to many researchers, buildings cultivating microalgae for energy production are the most promising direction in the construction of self-sufficient cities of the future. In addition, the algae biomass is well proven as an environmentally friendly building material. The world's first prototype of a residential building that provides itself by electricity due to algae grown directly on the facade is the project BIQ House, which was presented at the International Exhibition in Hamburg in 2013. This project is a joint development of the international design 
firm Arup, German consulting firm Strategic Science Consultants (SSC) and the Austrian architectural firm Splitterwerk Architects [12]. Using algae for electricity and heat generation has been studied by many researchers for several years. Among them the French architectural bureau X-TU, which is supported by laboratory CNRS "Gepea" from Nantes University started the project "Symbio2". The first stage of the experiment is concentrated on designing of photobioreactors on the facade in Saint-Nazaire, near the laboratory Gepea. Then, based on the results obtained by research, it is planned to move to the industrial stage. It includes developing of reactors incinerator Alcéade Nantes. According to the developers, the use of microalgae will help reduce energy consumption by more than $50 \%$ [13]

Applying the ideas of these technologies to our facility, we get, firstly, the ability to close flows of matter and energy in the system through the process of oxidation (combustion) of biomass for generation energy, and secondly, the absence of any limitations on the amount of produced biomass. Dynamics of processes into the phobiotoreactor depends on the illumination and the concentration of the carbon dioxide and nitrogen and phosphorus compounds. In photobioreactor 1, carbon dioxide, nitrogen and phosphorus come both from the reactor mineralizer and with the flue gases products of combustion of biofuel obtained from excess biomass. At the same time, microalgae purify the flue gases completely. Flue gases supply mode (mode of biomass burning) can be one more control parameter of the system.

The next step is a statement of simulation and control problem of the dynamics of the structure Microalgae-Mineralization.

\section{Simulation and Control of Artificial Ecosystems}

\subsection{Specificity of Research in the Field of Mathematical Ecology}

The end of the 20th and the beginning of the 21st centuries have been marked by the rapid growth of works in the biological sciences and related disciplines. Along with the rapid accumulation of experimental material occurs the development of life science theory. Partly, the new results in the biological sciences are currently obtained with the help of mathematical modeling. New subject areas such as mathematical biology, biophysics, and ecology have been developed. However, specificity of studies in mathematical biology and ecology is such that, until recently, the main array of models includes either systems of ordinary differential equations or balance models. Presence of a number of complex models based on partial differential equations was seen as exotic supplement to tried and tested mathematical apparatus. This is due to the facts that, firstly, one of the main difficulties in the mathematical modeling of the biology and ecology is that the correct use of models requires meaningful problem statements. Obtaining such settings is possible only through close contact between experts in different subject areas. Often, without such interaction, biologists are unable to translate correctly seemingly obvious concepts of their subject area into the language of mathematics. At the same time models developed by mathematicians without the participation of biologists and environmental engineers can be pure abstractions, which are far from the practical use. Secondly, models of reaction-diffusion type may be rather "unpleasant". For example, they are able to produce various kinds of instabilities and cause spatially inhomogeneous structures and self-oscillatory regimes. All this is enhanced by the presence of flow in the system.

Unlike traditional engineering approach, we propose to use complex mathematical model of photo- and bioreactor in the form in the form of the laws of conservation of mass and momentum and a control problems for them. This mathematical model forming the basis for automated control system is a major instrument to compensate for the human factor and provide robust work of the treatment facilities of such a small volume

\subsection{Statement of a Primal and Control Problems}

Dynamics of elementary volume biochemical reactor can be written in vector form using the laws of conservation of mass and momentum $[3,4,5]$

$$
\begin{gathered}
\frac{\partial S}{\partial t}=-U \cdot \operatorname{grad}(S)+\operatorname{div}(D \operatorname{grad}(S))+W, \\
W=N \mu,
\end{gathered}
$$

$$
\begin{gathered}
\frac{\partial U}{\partial t}=-U \cdot \operatorname{div}(U)+\operatorname{div}(v \operatorname{grad}(U)- \\
-\frac{1}{\rho} \operatorname{grad}(P)+G, \\
\operatorname{div}(U)=0,
\end{gathered}
$$

where $S$ is the vector of concentrations of substances, $N$ is the matrix of stoichiometric coefficients, $\mu$ is the 
vector of the rates of biochemical reactions, $W$ is the reaction term, $D$ is the vector of diffusion coefficients, $U$ is the flow velocity vector, $P$ is pressure, $G$ is the vector field of mass forces, $\rho$ is density.

In the final version of the model, the flow equations are reduced to Saint-Venant equations. The problem is formulated as a boundary value problem defined on a stratified set containing 1D and 2D area. Desilter model includes equations of flow and transport of suspended particles and the deformation of the layer of sludge. For photoreactor we use a model that is similar to [14]. The growth rate of biomass in photoreactor hyperbolically dependent on internal concentrations of nutrients (Droop model) [15]. Making a start from the analysis of models given in [16, 17], for reactor-mineralizer, we have chosen a model which takes into account the processes of biological phosphorus removal and nitrification inhibition by high doses of ammonium.

Further, we have to solve the problem of finding the optimal mode of the system. Boundary conjugation conditions subdomains of stratified set are controlled equations. Control variables are water rates at the connection points of subdomains 1, 3, 4 and the oxygen concentration at the 3 . Also the flue gases flow rate can be added to the control parameters.

All equations are linearized. The time axis is divided into sections with assumption about the constancy of controls. Features of this method of adjoint equations are described by us in detail in $[18,19]$. As a result, our problem is reduced to a series of linear programming problems, which allows us to significantly reduce the problem and perform almost real time control despite the complexity of underlying model.

\section{Conclusion}

The paper proposes a concept of treatment facilities, which can be used for water purification within residential building. The basic idea started from the conception of closed ecological LLS initially created for long-duration space flights. A distinctive feature of the project is a high degree of closure of matter flows in the system. The proposed technological scheme integrated in a building, is able to provide an autonomous existence for residents for a long time, for example as in a case of the harsh climatic conditions, with partial closure of the needs for water, pure atmosphere, decontamination and disposal of waste water. It also has the high efficiency of wastewater treatment, as it allows to partially replace the aeration by the natural process of water oxygenation during photosynthesis. A biomass formed as a result of the cleaning process can be processed into biofuel and provide a source of clean energy.

To create the robust work of closed exchange cycle and its components it is necessary to forming simulation model of processes. In this article, as the simulation model, we propose to use an initial boundary value problem for the linearized equations of ReactionAdvection-Diffusion and flow defined on stratified set. As a method for solving the optimal control problem, the best way is to use the adjoint equations method with an assumption about the constancy of controls during of some periods. In this case, the problem is reduced to the linear optimization problem and can be underlying for real-time control.

Further, a controlled closed-loop purification systems are being integrated in a building through the self-sustaining, interchangeable and standardized platforms, so-called mainboard-inspired one, situated beneath a modular home and controlling all water installments and energy components needed for a household, that being developed in [8]

\section{Acknowledgments}

The authors express their gratitude to Pavel Ermachenko for productive discussion of material of the article.

This work is in part funded by the Erasmus Mundus Action 2 programme of the European Union

\section{References}

[1] Nelson M., Pechurkin N.S., Allen J.P., Somova L.A., and Gitelson J.I. Bioengineering of Closed Ecological Systems for Ecological Research, Space Life Support and the Science of Biospherics, ENVIRONMENTAL BIOTECHNOLOGY in the Handbook of Environmental Engineering series, Chapter 11 in Volume 10, 2010, The Humana Press, Inc., Totowa, New York, 2010.

[2] Sychev V.N., Levinskikh M.A., and Shepelev Ye.Ya. Biological components of LSS for a Martian expedition. Adv Space Res, 31(7): 16931698, 2003.

[3] Astrakhantsev G.P., Rukhovets L.A., and Menshutkin V.V. Development of Lake Ladoga ecosystem models: modeling of the phytoplankton succession in the eutrophication process, Ecological Modelling, 165(1): 49-77, 2003.

[4] Astrakhantsev G.P. and Rukhovets L.A. A threedimensional model of transformation of biogenes and organic matter in lakes, Russ.J.Numer.Anal. Math.Model, 9(1): 1-12, 1994.

[5] Bulgakow A.G., Buzalo N.S., Zhmenya E.S., and Zaharchenko N.S. Simulation and Optimization in the Control Problem of the Biosphere Compatible Water Utilization System in Urbanized Territories 
(in Russian), Journal of South-Western State University, 5-2 (44): 136-154, 2012.

[6] Osipov V.I. History of natural disasters in the world (in Russian), Problems of ecology. Bulletin of the Russian Academy of Sciences, 74(11): 998-1005, 2004.

[7] Global Environment Outlook - 3. Past, present and future perspectives. (Editor of the Russian edition GN Golubev), UNEP, M. Interdialect, Moscow, 2002.

[8] Linner T., Thuesen C., and Bock T. Networked Energy Platforms: A New Concept for Closed Loop Resource Utilization in Open Building Systems. In Proceedings of FISC 2010 First International Conference on Sustainability and the Future, pages 706-616, British University in Egypt, Elain Publishing, Cairo, Egypt, 2010.

[9] Bock T. and Linner T. From Space System Engineering to Earth System Engineering: A new Method for Developing Technologies being compatible with Society, Ecology and Economy. In Proceedings of FISC 2010 First International Conference on Sustainability and the Future, pages 389-399, British University in Egypt, Elain Publishing, Cairo, Egypt, 2010.

[10] Sychev V.N. Study of the effects of weightlessness on biological objects: links of closed ecological life support systems and the development of technologies of their cultivation (in Russian). Habilitation thesis. Scientific library of theses and abstracts disserCat. On-line: http://www.dissercat.com/content/issledovanievliyaniya-nevesomosti-na-biologicheskie-obektyzvenya-zamknutykh-

ekologicheskik\#ixzz2rhXaDvo4, Accessed: 28/01/2014.

[11] Shegolkova N.M. and Shashkina P.S. A photobioreactor for tertiary sewage treatment from nutrients and disinfection (in Russian). On-line: http://www.mosvodokanal.ru/index.php?newsid=57 86, Accessed: 28/01/2014.

[12] Smart Material Houses. BIQ. International Building Exhibition IBA Hamburg. On-line: http:// www.iba-hamburg.de/en/themes-projects/thebuilding-exhibition-within-the-buildingexhibition/smart-materialhouses/biq/projekt/biq.html, Accessed: 29/01/2014.

[13] Algocultures. Exposure and public laboratory of architecture for the construction of bio-facades. Algocultures, exhibition at Pavillon de l'Arsenal, 2013. (in French). On-line: http:// www.pavillonarsenal.com/en/expositions/thema_modele.php?id_ exposition=272, Accessed: 29/01/2014.

[14] Levich A.P. Art and technique of system modeling: variation methods in community ecology, structural and experimental principles, categories and functors (in Russian). Institute of Computer Science, Moscow-Izhevsk, 2012.

[15] Droop M.R. The nutrient status of algal cells in continuous culture. J. Mar. Biol. Assoc. U.K, 54:825-855, 1974

[16] Henze M., Harremoes P., la Cour Jansen J., and Arvin E. Wastewater treatment, biological and chemical processes. Springer Verlag, Germany, 1995.

[17] Riznichenko G.Y. Mathematical models in biophysics and ecology (in Russian). Institute of Computer Science, Moscow-Izhevsk, 2013.

[18] Buzalo N., Zhmenya E., Ermachenko P. Control of Substance Concentrations in Natural and Artifcial Aquatic Ecosystems in Problems of Management of Biosphere Compatible Technical Systems In Proceedings of the CIB*IAARC W119 CIC 2013 Workshop "Advanced Construction and Building Technology for Society”, pages 49-55, Technische Universität München (TUM), Germany, 2014.

[19] Bulgakow, A.G., Buzalo, N.S., Zhmenya, E.S., and Zaharchenko N.S., Simulation and Optimization in the Control Problem of the Biosphere Compatible Water Utilization System in Urbanized Territories (in Russian). Journal of South-Western State University, 5-2 (44), pp. 136-154, 2012. 